\title{
Inquiry-Based Learning in Sustainability Science
}

\author{
Ulli Vilsmaier and Esther Meyer
}

Inquiry-based learning is a key component of degree programs in sustainability science. Since the research field focuses on sustainability challenges, which often require an interdisciplinary or transdisciplinary approach, students are not only introduced to the basics of sustainability science, but also trained in cooperative forms of research. Thus a variety of study objectives are combined, which can be very well implemented in the mode of inquiry-based learning.

\subsection{Characteristic Features in Sustainability Science as a Context for Inquiry-Based Learning}

Sustainability science is a recently created field of research, which has developed in response to the discourse on sustainable development to address sustainability-related societal challenges. The concept of "sustainable development" was introduced by the United Nations' Brundtland Commission in 1987. It has become significantly more differentiated since the United Nations Conference on Environment and Development in Rio de Janeiro in 1992, and has entered into the international public discourse. It is informed

U. Vilsmaier, Prof. Dr. ( $\square)$

Leuphana Universität Lüneburg, Methodenzentrum und Institut für Ethik und Transdisziplinäre Nachhaltigkeitsforschung, Apl. Prof. für Transdisziplinäre Methoden,

Lüneburg, Germany

e-mail: vilsmaier@leuphana.de

E. Meyer, M.Sc.

Leuphana Universität Lüneburg, Institut für Ethik und Transdisziplinäre

Nachhaltigkeitsforschung, Lüneburg, Germany

e-mail: esther.meyer@leuphana.de

H. A. Mieg (ed.), Inquiry-Based Learning - Undergraduate Research, https://doi.org/10.1007/978-3-030-14223-0_31 
by research on questions about the future, environmental problems, justice and other topics; however, it is not a result of scientific research, but rather an ethical concept (Michelsen and Adomßent 2014). The ethically motivated core demands formulated in the final report of the Brundtland Commission, "Our Common Future," include preserving the environment, achieving social justice and ensuring political participation (ibid.). To achieve this, the Action Plan approved at the Rio de Janeiro UN Conference in 1992 highlighted the role of science and the importance of cross-boundary research and a strong societal contextualization of science for sustainable development. In Agenda 21, Section 31.1, it states:

The cooperative relationship existing between the scientific and technological community and the general public should be extended and deepened into a full partnership. [...] Existing multidisciplinary approaches will have to be strengthened and more interdisciplinary studies developed between the scientific and technological community and policy makers and with the general public to provide leadership and practical know-how to the concept of sustainable development. The public should be assisted in communicating their sentiments to the scientific and technological community concerning how science and technology might be better managed to affect their lives in a beneficial way. (Agenda 21, Section 31.1)

The field of sustainability science emerged out of different disciplines and interdisciplinary fields of research at the turn of the millennium. The environmental sciences, global change research, social-ecological research and human ecology played an essential role. The cohesive factor in this heterogeneous research field lies in its normative orientation towards sustainable development and thus in dealing with problems (Klein 2014, p. 74, Ziegler and Ott 2015) "that jeopardize the long-term ability to safeguard conditions for societal development" (Michelsen and Adomßent 2014, p. 43, translated) as well as solutions that enable sustainable development. In 2003, Clark and Dickson characterize sustainability science as a vibrant field that brings together different perspectives from the natural, social and engineering sciences and medicine, as well as from fields of practice, incorporating perspectives from the global north and south, but that is not yet an independent discipline itself (Clark and Dickson 2003, p. 8060).

Since then, numerous steps towards institutionalization have been taken. The number of journals that include the term sustainability in their title has increased significantly. Numerous academic institutes, chairs and degree programs on sustainability, sustainable development and sustainability science(s) have been established. In 2010, the first Faculty of Sustainability in Germany was founded by Leuphana University in Lüneburg. In the field of sustainability science, internal structures are increasingly becoming apparent. Nölting, Voß and Hayn suggest drawing a distinction between three levels of sustainability research: the analytical level, which aims to create systems knowledge; the normative level, at which target and orientation knowledge is developed; and the operational level, at which conceptual or transformation knowledge is generated (Nölting et al. 2004, p. 254, cited in Michelsen and Adomßent 2014, p. 43). This division emphasizes that, according to its normative foundations, sustainability science not only aims to understand and 
explain, but equally aims at transformation. Therefore, different forms of research are required to produce different types of knowledge.

In addition to established empirical and interpretative forms of research, transdisciplinary sustainability research has developed as a core pillar of sustainability science. It is an integrative form of research that transcends disciplinary and interdisciplinary research by addressing societal issues "in vivo," i.e. in their living context, together with societal actors who are related to the respective problem (Vilsmaier and Lang 2014). In this sense, transdisciplinary research is a cooperative form of research, which comprises not only scientists from different disciplines, but also actors from different social fields as researchers. It not only develops knowledge about a problem, but also induces a negotiation and design process to bring about solutions to a given problem.

Learning and experiencing transdisciplinary research practice has a prominent position in the education of sustainability scientists. Transdisciplinary sustainability research neither follows a consistent framework nor builds on an established body of knowledge, but rather requires the establishment and implementation of research processes for specific cases and contexts. Therefore, learning through experimentation and reflective learning have a prominent position (Michelsen and Adomßent 2014). Transdisciplinary sustainability research is therefore conducted in an inquiry-based learning mode.

\subsection{Characteristics of Inquiry-Based Learning in Sustainability Science}

For students of sustainability science, the heterogeneity of the subject requires not only a wide range of sustainability knowledge and research forms, but also a high degree of individual responsibility in developing their professional profile. Therefore, inquiry-based learning in cooperative, transdisciplinary projects provides a suitable framework. It provides students with the opportunity to complete an entire research process in a very independent and autonomous manner (Huber 2009). On the other hand, they acquire new content, methods and abilities independent of an instructor's program or a static curriculum. Furthermore, the learning process is strongly guided by students' particular interests and requirements related to the given research situation. Specifics of inquiry-based learning in sustainability science include:

Problem Orientation Research questions are derived from concrete societal issues and require a case-based development of research designs as well as integrating heterogeneous bodies of knowledge that draw on different subjects and disciplines. Inquiry-based learning in sustainability science therefore makes working in a problem-oriented, interdisciplinary manner a necessity. This includes the constitution of fields of research that often exist between established subjects and disciplines, and which are yet to establish a firm place in the landscape of knowledge. A challenge faced by students of sustainability 
science is in acquiring familiarity with the sustainability-relevant body of knowledge in order to be able to address the issues of concern.

Solution Orientation In sustainability science, the normativity of a science for sustainable development is accompanied by a solution orientation in research, which requires the production of different types of knowledge (systems knowledge, target knowledge, transformation knowledge) and the negotiation and processing of societal transformations. Inquiry-based learning in sustainability science is therefore characterized by mutual learning in cooperative, transdisciplinary settings (Vilsmaier et al. 2015). Students are particularly challenged by gaining an appropriate understanding of the role(s) as sustainability scientists, and by being confronted with different interests and multiple objectives in the research process.

Relatedness to a Case The orientation towards a concrete societal sustainability challenge requires case-based, transdisciplinary research, which encompasses a variety of analytical dimensions (Scholz and Tietje 2002). It claims to produce generalizable knowledge in addition to results for the specific case. Inquiry-based learning in sustainability science therefore requires a combination of idiosyncratic and nomothetic research (Krohn 2008), and often of qualitative and quantitative research (Scholz and Tietje 2002). Above all, these are associated with challenges in the formation of theoretical foundations and methodical designs. Sustainability science students therefore need a solid epistemological and methodological understanding.

Difference-Based Transdisciplinary sustainability research is an integrative form of research that aims to integrate different bodies of knowledge, models of research and cultures of cognition, perspectives and interests, as well as values and objectives. In order to achieve this, it is necessary to identify differences and make them accessible. Inquirybased learning in sustainability science therefore requires the ability to identify and to deal with differences. Students are required to learn to read both their own position in the research process, their perspective and socialization within a particular research culture, their interests and objectives, as well as the positions and perspectives of others in order to facilitate integrative research (cf. Vilsmaier and Lang 2015).

Plurality of Methods Sustainability research requires a broad spectrum of methods that are applied in an integrative way. In addition to methods of empirical and interpretative research, different methods of cooperation, evaluation, research management and boundary work are used to elaborate on differences between perspectives, bodies of knowledge and roles in the research process. In this sense, inquiry-based learning in sustainability science requires not only the knowledge or appropriation of different methods, but also the ability to link and embed different types of methods. Thus, students of sustainability sciences require extensive methodological knowledge in combination with basic theoretical and methodological understandings that make possible integrative forms of research. 


\subsubsection{Inquiry-Based Learning in the Master's Degree Program in Sustainability Science at Leuphana University of Lüneburg}

An example of inquiry-based learning in sustainability is the module "Transdisciplinary Projects" in the master's degree "Nachhaltigkeitswissenschaft - Sustainability Science" at Leuphana University of Lüneburg. The module covers two semesters and comprises 20 ECTS credits. It forms the core of the master's program and enables students to spend more than a year researching concrete sustainability challenges within the university's regional environment. Generally, there are three groups each year, with approximately 15 students working together with two lecturers and one tutor, as well as non-university actors, forming three team levels.

Level 1: The student team. It consists of students with usually very heterogeneous professional backgrounds. The bachelor's degrees of students in the master's program include studies from the natural sciences, social sciences, and the humanities. Student teams are therefore always multidisciplinary. They work together continuously over a 12-month period.

Level 2: The academic team. In addition to the students, this team includes the lecturers and the tutor. In team teaching, attention is paid to a multidisciplinary composition in which one person contributes theoretical-methodological expertise in the field of transdisciplinary research. Lecturers meet with the student group on a selective basis, usually once a week during the lecture period and on request.

Level 3: The transdisciplinary team. In addition to the students, teachers and tutors, this team includes actors from the field that is being studied in the transdisciplinary research project. The number and heterogeneity of the actors is variable depending on the case. Since the establishment of the transdisciplinary team itself is already a core learning step, it is usually only in the second half of the project that regular collaboration takes place, which can range from joint workshops to regular meetings in a steering committee.

According to the principles of inquiry-based learning (Huber 2009), students are given a great deal of autonomy at all levels. The specifications that students receive are first and foremost of a theoretical and methodological nature. They are taught in an accompanying lecture during the first semester. The lecture covers fundamentals of transdisciplinary research and process design. Furthermore, the students are supported by the instructors through specific lectures on request, and are guided to find important literature. In order to promote the principle of independent research, optional accompanying workshops are offered in which students can deepen their specific expertise and exchange perspectives and experiences on specific topics or aspects of the research process with fellow students from other project groups.

The transdisciplinary projects are based on the principles of transdisciplinary sustainability research developed by Lang and colleagues (Lang et al. 2012). The students' 
research process is divided into three phases (cf. Lang et al. 2012; Vilsmaier and Lang 2014). Phase 1 covers a variety of subject- and team-related tasks that serve to constitute the field of research. In phase 2, the research question is processed according to a research plan and solution-oriented knowledge is produced at the different team levels. Finally, Phase 3 serves to link the knowledge gained to scientific discourses on the one hand, and to societal contexts on the other. This should ensure that the results of the transdisciplinary research process are brought to fruition.

Phase 1: The constitution of the field of research. Students identify sustainability challenges in a given subject area (e.g. phosphorus management, community development, energy supply) supported by the instructors. In an iterative procedure, a research question is developed that is of interest from a scientific perspective and at the same time socially relevant. Students analyze the relevant state of the art and the societal preconditions for achieving sustainable development. Already in the course of developing the research question, students begin to collaborate with actors from the field, thereby taking into account heterogeneous perspectives on the issues of concern. This is the first step toward to building a transdisciplinary team. These initial tasks assist the students in forming a team and developing working structures. The potential of the multidisciplinary group as well as individual interests and learning objectives are made visible, roles and responsibilities are distributed among the students, and a project management is established. Phase 1 is completed upon the submission of a research plan after 6 months. At this point, students have elaborated the state of the research, built up and expanded the necessary knowledge and expertise in the group, and established collaboration routines as student and academic teams. The transdisciplinary team should be organized at this point (e.g. by establishing a steering committee).

Phase 2: Processing the research question. Based on the research plan and the established team and work structure, in-depth knowledge about the problem (system knowledge), objectives to be achieved (target knowledge) and knowledge about how desired goals can be achieved (transformation knowledge) is acquired in phase 2. Academics and actors from the field have different roles and tasks in the research process. In order to gain a better understanding of the problem, the plurality of perspectives and the corresponding knowledge and experience are developed and integrated. For example, students and teachers introduce scientific knowledge of the subject, while actors from the field bring knowledge acquired through professional practice or everyday routines. The integration of different bodies of knowledge aims at a deeper or even new understanding of a problem and is a key element of transdisciplinary research, which is methodically implemented by the students. In developing target knowledge, the heterogeneity of interests and goals of different actors comes into its own. Students play a central role in shaping a societal learning process. Phase 2 ends with the completion of the survey and integration of knowledge in the different dimensions. At the end of Phase 2, transformation is likely to have already begun, due to the fact that, by working in transdisciplinary teams, societal learning processes are induced. New constellations of actor in the field are formed, creating 
communicative spaces and cooperation opportunities, and may contribute to sustainability transformations.

Phase 3: Re-integration of results into scientific communities and societal fields. The results of a transdisciplinary project are prepared in various ways. Contributions are made to the scientific discourse and the specific case. Students write a scientific paper, which they prepare for potential publication in the journal "GAiA - Ökologische Perspektiven für Wissenschaft und Gesellschaft" ("GAiA - Ecological Perspectives for Science and Society"). In addition, the outcomes are prepared for relevant actors or societal fields. The form, language and type of content are adapted to the target group. Recommendations for action are also provided, and results are presented to relevant actors, e.g. to the Environment Committee of the City of Lüneburg. Phase 3 ends with a public presentation of the projects and research results, which brings together all actors involved, as well as the interested public. The informal part of the event serves to strengthen relationships between actors from different sectors of society, students and scientists, and offers the opportunity to explore further topics and forms of cooperation. For students, the research and cooperation ends upon submission of the paper and the handouts for practice. Nevertheless, for many of them, the continuity or implementation of results is important. Thus, it is not unusual for individual students to maintain contact or co-design follow-up activities beyond the duration of the course.

\subsection{Conclusion: Potentials and Challenges of Inquiry-Based Learning in Sustainability Science}

Sustainability science provides a basis for dealing with phenomena or problems not through objectivation and linear cause-and-effect relationships, but rather in a vivid way that takes into consideration the complexity of real-life situations and challenges. The shift in the research process is far-reaching. With Nicolescu, we can speak of a shift from "in vitro" to "in vivo" research (Nicolescu 2008) and, as a corollary, of overcoming the dichotomy of active research subjects on the one hand, and of passive research objects on the other (Vilsmaier and Lang 2014). Here a research topography crystallizes, which forms a new topos in the landscape of research. It spans the gap between the spheres of science that focus on generalizability, traceability and stability, and those concerned with the elusiveness of an ever-changing world. Transdisciplinary sustainability research can combine these two spheres by addressing case-based sustainability challenges. It uses existing knowledge and creates new knowledges and experiences when working on the case, and situated within the case, and thereby promotes the transformation of the concrete lifeworld situation.

By practicing transdisciplinary sustainability research in the mode of inquiry-based learning, the learning process combines the acquisition of theoretical knowledge, the rehearsal of research practices to generate new knowledge, and the shaping of societal transformation processes. Inquiry-based learning in sustainability science, based on 
concrete lifeworld situations is thus always learning for sustainable development. These constellations challenge students to actively position themselves in relation to the research field, which loses its object status. However, this normative moment of inquiry-based learning in sustainability science needs to be handled with caution so that students are not driven either into mere activism or traditional research based on separation (Latour 2002). The establishment of a new, cooperative research culture requires comprehensive reflection. It must make the issue of objectivation and its causes itself the object of reflection in order to challenge students' dedication in the struggle for a new form of research and the consolidation of positions and roles of (prospective) sustainability scientists. Like transdisciplinary research itself, this reflection is not a fixed program, but instead arises from the experience of a vivid research situation, which is experienced by learning.

\section{References}

Agenda 21: Retrieved 05 March 2019 from http://www.un-documents.net/a21-31.htm

Clark, W.C./Dickson, N.M. (2003). Sustainablity science. The emerging research program. Proceedings of the National Academy of Science, 100, 8059-8061.

Huber, L. (2009). Warum Forschendes Lernen nötig und möglich ist. In L. Huber/J. Hellmer/F. Schneider (Hrsg.), Forschendes Lernen im Studium. Aktuelle Konzepte und Erfahrungen (S. 9-36). Bielefeld: UniversitätsverlagWebler.

Klein, JT. (2014). Discourses of transdisciplinarity: Looking back to the future. Futures, 63, 68-74.

Krohn, W. (2008). Learning from Case Studies. In G. Hirsch Hadorn/H. Hoffmann-Riem/S. BiberKlemm/W. Grossenbacher-Mansuy/D. Joye/C. Pohl/U. Wiesmann/E. Zemp (Hrsg.), Handbook of transdisciplinary research (S. 369-384). Berlin: Springer.

Latour, B. (2002). Die Hoffnung der Pandora. Frankfurt a.M.: Suhrkamp.

Lang, D.J./Wiek, A./Bergmann, M./Stauffacher, M./Martens, P./Moll, P./Swilling, M./Thomas, C. (2012). Transdisciplinary Resarch in Sustainability Science - Practice, Principles, and Challenges. Sustainablility Science, 7/1, 25-43.

Michelsen, G./Adomßent, M. (2014). Nachhaltige Entwicklung: Hintergründe und Zusammenhänge. In H. Heinrichs/G. Michelsen (Hrsg.), Nachhaltigkeitswissenschaften (S. 3-60). Berlin, Heidelberg: Springer Spektrum.

Nicolescu, B. (2008). In Vitro and In Vivo Knowledge - Methodology of Transdisciplinarity. In B. Nicolescu (Hrsg.), Transdisciplinarity. Theory and Practice (S. 1-22). Cresskill: Hampton Press.

Nölting, B./Voß, J.-P./Hayn, D. (2004). Nachhaltigkeitsforschung - jenseits von Disziplinierung und »anything goes «. GAIA 13, 4/2004, 272-279.

Scholz, R.W./Tietje, O. (2002). Embedded case study methods. Integrating quantitative and qualitative knowledge. Thousand Oaks: Sage Publications.

Vilsmaier, U./Lang D. J. (2015). Making a difference by marking the difference: constituting inbetween spaces for sustainability learning. Current Opinion in Environmental Sustainability, 16, $51-55$.

Vilsmaier, U./Engbers, M./Luthardt, P./Maas-Deipenbrock, R.-M./Wunderlich, S./Scholz, R.W. (2015). Case-based Mutual Learning Sessions. Knowledge integration and transfer in transdisciplinary processes. Sustainability Science, 10, 563-580. 
Vilsmaier, U./Lang, D. J. (2014). Transdisziplinäre Forschung. In H. Heinrichs/G. Michelsen (Hrsg.), Nachhaltigkeitswissenschaften (S. 87-114). Berlin, Heidelberg: Springer Spektrum.

Ziegler, R./Ott, K. (2015). The quality of sustainability science: A philosophical perspective. In:

J. Enders/M. Remig, Theories of Sustainable Development (43-64). London, New York: Routledge. Taylor \& Francis Group (Routledge Studies in Sustainable Development).

Open Access This chapter is licensed under the terms of the Creative Commons AttributionNonCommercial-NoDerivatives 4.0 International License (http://creativecommons.org/licenses/bync-nd/4.0/), which permits any noncommercial use, sharing, distribution and reproduction in any medium or format, as long as you give appropriate credit to the original author(s) and the source, provide a link to the Creative Commons licence and indicate if you modified the licensed material. You do not have permission under this license to share adapted material derived from this chapter or parts of it.

The images or other third party material in this chapter are included in the chapter's Creative Commons licence, unless indicated otherwise in a credit line to the material. If material is not included in the chapter's Creative Commons licence and your intended use is not permitted by statutory regulation or exceeds the permitted use, you will need to obtain permission directly from the copyright holder.

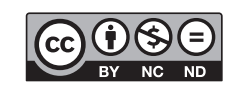

